\title{
The Improper Use of Fossil Nomenclature
}

\author{
STANLEY M. GARN \\ Center for Human Growth and Development, The University of Michigan, \\ Ann Arbor, Michigan 48104
}

\begin{abstract}
Retention of obsolete genera and species, and premature acceptance of provisional genera and species unnecessarily inhibit meaningful communication between students of fossil man.
\end{abstract}

A recurrent problem in teaching about fossil man is the continued use of nomenclature nearly as fossil. Though we all know better and think differently, Sinanthropus and Pithecanthropus are too-often italicized as still-valid genera, and even "Neanderthalensis" as a stillvalid species. Reviewing elementary texts introduced as late as 1968-70, and derived from both sides of the Atlantic, it is disconcerting to discover Pithecanthropus erectus, Sinanthropus pekenensis, Homo heidelbergensis and even Homo neanderthalensis. If italicization and binominal nomenclature are used with intent, it means that the authors of these texts accept these obsolete genera and species as still valid, including even Pithecanthropus robustus, which Weidenreich specifically introduced as "without taxonomic meaning."

A similar problem applies to a whole company of provisional labels, from Australopithecus and Paranthropus (italicized as generically separate from each other and from Homo) to Telanthropus, Prometheus, Tchadanthropus, Meganthropus, Atlanthropus, Homo habilis, and so on. It is apparently impractical to stop these proliferations by discoverers or describers, but little reason to accept most of them as more than specimen labels with but private meaning. And they ought not now be italicized as apparently valid genera and species to the everlasting confusion of neophytes and others not so new.

Now it is an old editorial rule that a writer has a right to write what he means. If he writes Pithecanthropus erectus, meaning the Javanese form as generically distinct from Homo, we may disagree with his decision, but not with his right to make the distinction. If a fossil discoverer coins a species other than sa- piens, he has that right under the peculiarly permissive conventions of human paleontology, but we have an equal right to disagree. However, when a textbook compiler uses one formal label in his writing yet clearly intends another, then the coprolites truly fly. How can a form be in two genera, simultaneously, in the same book or published paper?

Briefly stated, we face two (related) problems in fossil nomenclature. The first is the retention of obsolete genera and obsolete species no longer accepted, but fossilized in textbook writing both by italicization and binominal nomenclature. The second is the tacit acceptance of provisional genera and provisional species, italics and all, for no better reason than the fact that they have been proposed. In parsing the euphonious Graeco-Latin mouthfulls, how is the beginning student to realize that most are either obsolete or not acceptable, to the greater extent merely Homo under another name?

From manuscripts I have seen, even some professional anthropologists have come to be confused, apparently assuming that italicization is an attribution of dignity, much as we conventionally capitalize the name of the Deity. Some now write Australopithecine (italics theirs) or Pithecanthropoid (italics again theirs) or apply Pithecanthropus (nominum nudum) to a whole range of specimens of temporally and geographically diverse origins. It becomes more and more difficult to decipher what is actually intended in the matrix of what is written, to separate error from intent, or vice versa.

These strictures on the continued use of obsolete fossil nomenclature and difficulties in coping with provisional genera and proposed species of doubtful validity, are not meant to deny legitimate problems 
of subspecies. I hasten to propose Homo sapiens obscurus, following long-established tradition, should there be an appropriate sub-committee on zoological nomenclature. But when it comes to retention of no-longer valid genera and species, and acceptance of every classical. sounding combination of names, more than simple disapproval seems warranted. At the textbook level, those who read book manuscripts for publishers may complain mightily, and again when the textbook comes to journal review. Journal editors certainly may query intent, asking that authors justify their italics (in a footnote at least) when obsolete or provisional labels are employed.

Otherwise we are left with five or more apparent genera that are in effect but one (or at most 2) and 15-50 apparent species that resolve down to perhaps five at most. And if the books say one thing but mean another, how is the student to know? 